\title{
How Much of Hazardous Blue Light is Transmitted By Spectacle Lenses?
}

\author{
Saeed Rahmani ${ }^{1}$, PhD; Mohammadreza Nazari ${ }^{1}$, MS; Alireza Akbarzadeh Baghban ${ }^{2}$, PhD \\ Mohammad Ghassemi-Broumand ${ }^{1}$, MD \\ ${ }^{1}$ Department of Optometry, School of Rehabilitation, Shahid Beheshti University of Medical Sciences, Tehran, Iran \\ ${ }^{2}$ Proteomics Research Center, Department of Biostatistics, School of Allied Medical Sciences, Shahid Beheshti University of \\ Medical Sciences, Tehran, Iran \\ ORCID: \\ Saeed Rahmani: https://orcid.org/0000-0001-6330-4405
}

J Ophthalmic Vis Res 2020; 15 (3): 435-437

Dear Editor,

The first region of the visible light spectrum is called blue light. Blue light is beneficial to humans in color vision, night vision, and circadian rhythms. ${ }^{[1,2]}$ However, this type of light raises concerns as it carries high energy and can cause ocular damages, such as photic retinopathy. In addition to the sun, there are several artificial sources of blue light emission, such as lightemitting diodes (LEDs), light bulbs, and fluorescent light tubes. With the increasing use of digital bluerich LED-backlight displays, such as in mobile devices and tablets, users' eyes are more exposed to blue light. ${ }^{[2,3]}$ Blue light can also induce eyestrain, however, the blue light-blocking lenses may reduce eye fatigue. ${ }^{[4,5]}$

Currently, some lens manufactures claim that their products can alleviate eyestrain and ocular discomfort associated with the use of digital devices. ${ }^{[5]}$ This raises important questions about the efficacy of blue light-control lenses. Therefore,

Correspondence to:

Saeed Rahmani, PhD. Department of Optometry, School of Rehabilitation Sciences, Shahid Beheshti University of Medical Sciences, Opposite to Bou-Ali Hospital, Damavand Ave., Tehran, Iran. E-mail: medicalopto@yahoo.com

Received: Accepted:

\section{Access this article online}

Website: https://knepublishing.com/index.php/JOVR

DOI: 10.18502/jovr.v15i3.7465 eight blank-white spectacle lenses (four with and four without blue light-blocking property) were collected from different optical companies. A spectrophotometer (Cecil Instrument, UK) was used to measure the blue light transmission. Three ranges of blue light were evaluated: $400-450 \mathrm{~nm}$, 455-500 nm, and 400-500 nm. For the statistical analysis, non-parametric Mann-Whitney test was employed. A P-value $\leq 0.05$ was considered statistically significant.

The mean transmission of blue light through lenses with and without blue light-blocking coating in the range of $400-455 \mathrm{~nm}$ were $58.76 \pm 3.01 \%$ and $83.10 \pm 1.71 \%$, respectively. The differences were statistically significant $(P=0.02)$. The harmful portion of blue light is accumulated in this range as previous studies have shown that using filters capable of $50 \%$ reduction in $430 \mathrm{~nm}$ blue light transmission can prevent approximately $80 \%$ of photochemical damage to the retina. Notably, there is currently no strict guideline for blue lightblocking coatings. ${ }^{[2]}$

The mean transmission of blue light through lenses with and without blue light-blocking coating in the range of $455-500 \mathrm{~nm}$ were $95.58 \pm 0.46 \%$ and $96.00 \pm 0.57 \%$, respectively. The differences were not statistically significant $(P=0.39)$. Higher

This is an open access journal, and articles are distributed under the terms of the Creative Commons Attribution-NonCommercial-ShareAlike 4.0 License, which allows others to remix, tweak, and build upon the work non-commercially, as long as appropriate credit is given and the new creations are licensed under the identical terms.

How to cite this article: Rahmani S, Nazari M, Baghban AA, GhassemiBroumand M. How Much of Hazardous Blue Light is Transmitted By

Spectacle Lenses?. J Ophthalmic Vis Res 2020;15:435-437. 


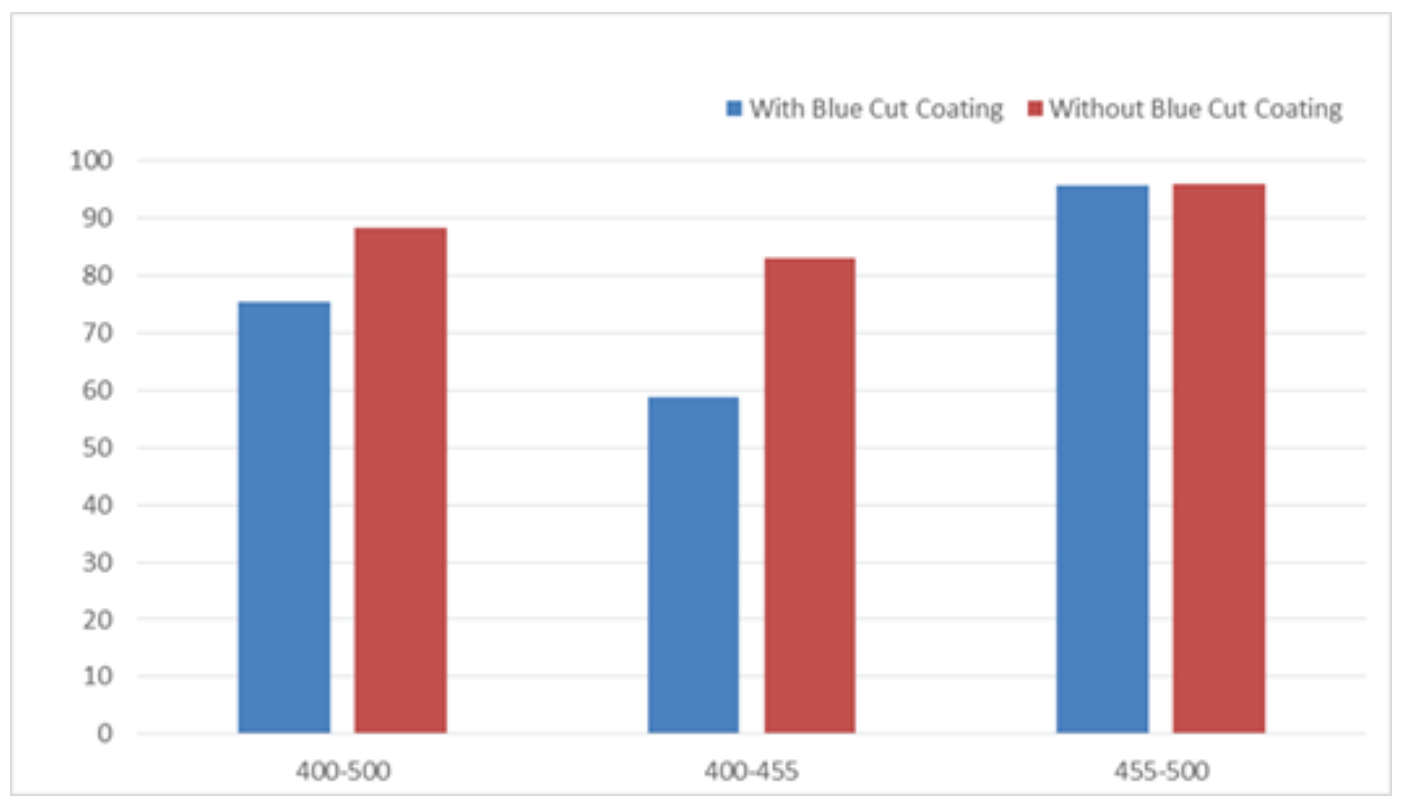

Figure 1. Blue light transmission of lenses with and without blue light-blocking property in different wavelengths.

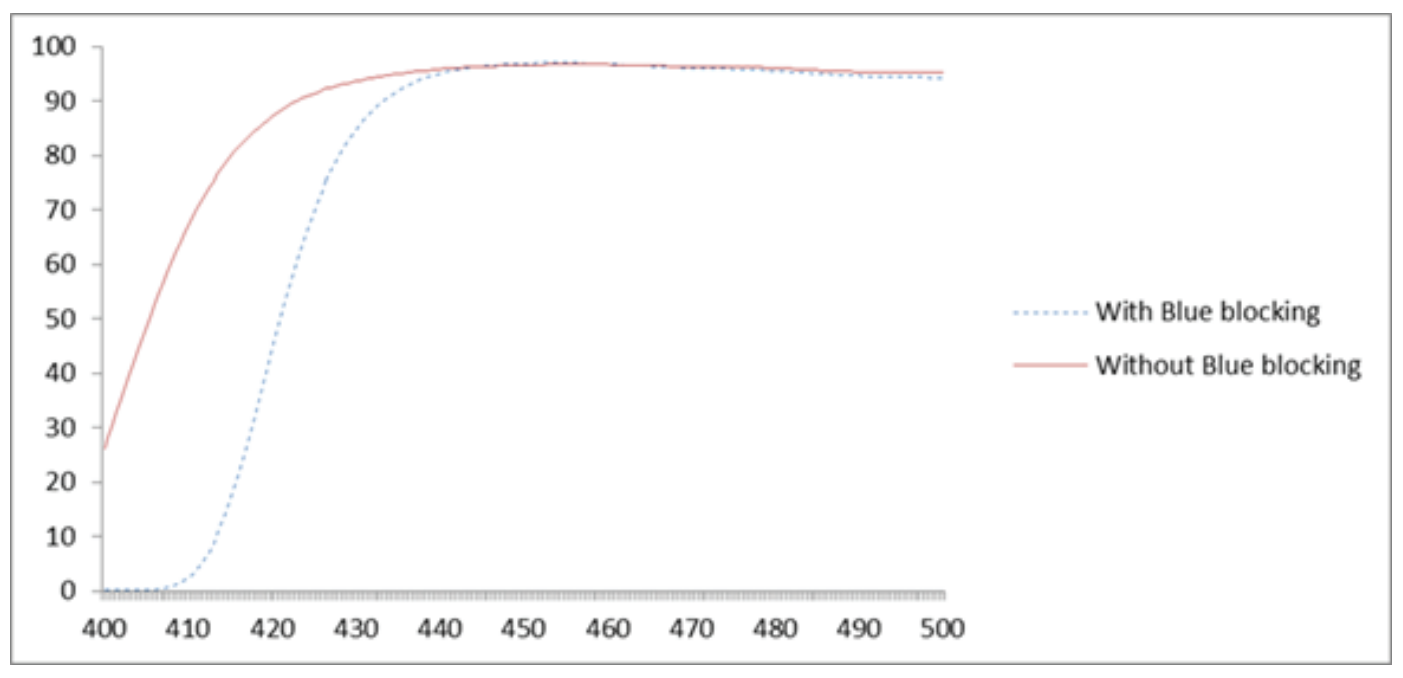

Figure 2. Comparison between spectral transmittance of lenses with and without blue light-blocking property.

wavelengths, that is, $455-500 \mathrm{~nm}$, are considered useful light for color vision and circadian rhythm.

The mean transmission of blue light through lenses with and without blue light-blocking coating in the range of $400-500 \mathrm{~nm}$ were $75.33 \pm 1.51 \%$ and $88.40 \pm 1.63 \%$, respectively. The differences were statistically significant $(P=0.02)$. The lenses with blue light-blocking property could reduce the blue light transmission by approximately $25 \%$ in the wavelength range of $400-500 \mathrm{~nm}$. Thus, the filtering value was twice the amount in the lenses without blue light-blocking property (Figures 1 and 2).
Finally, the spectacle lenses with blue lightblocking property could effectively attenuate hazardous lights. It is recommended to use the spectacle lenses that are equipped with blue light-blocking coating to reduce the risk of ocular diseases attributed to hazardous blue light.

\section{Acknowledgments}

The authors thank the Research Affairs of the Shahid Beheshti University of Medical Sciences for their support. 


\section{Conflicts of Interest}

There are no conflicts of interest.

\section{REFERENCES}

1. Giannos SA, Kraft ER, Lyons LJ, Gupta PK. Spectral evaluation of eyeglass blocking efficiency of ultraviolet/high-energy visible blue light for ocular protection. Optom Vis Sci 2019;96:513-522.
2. Leung TW, Li RW, Kee CS. Blue-light filtering spectacle lenses: optical and clinical performances. PLOS ONE 2017;12:e0169114.

3. Smith BT, Belani S, Ho AC. Ultraviolet and near-blue light effects on the eye. Int Ophthalmol Clin 2005;45:107-115.

4. Ide T, Toda I, Miki E, Tsubota K. Effect of blue lightreducing eye glasses on critical flicker frequency. Asia Pac J Ophthalmol (Phila) 2015;4:80-85.

5. Downie LE. Blue-light filtering ophthalmic lenses: to prescribe, or not to prescribe? Ophthalmic Physiol Opt 2017;37:640-643. 